\title{
Postmodern Sanatın Anlamlandırılması ve Bireyin Iç Huzursuzluğu
}

\author{
A. Cem Özal \\ Muğla Sttkı Koçman Üniversitesi Eğitim Fakültesi \\ E-mail: cemozal@mu.edu.tr
}

\section{$\ddot{O} z$ et}

Sanat ortaya çıktığ zaman diliminden bu yana bir üst yapı kurumu olarak dönemlere göre değişsenlik gösteren işlevler üstlenmişti. Bilgi verme, tanıklık etme, algl yönetme, ifade etme, belgelendirme gibi pek çok nedenle yapılmış olan sanat eserlerini biliriz. Mağara dönemlerindeki büyücülerin, Ortaçağdaki din adamlarının, Rönesanstaki burjuva sınııinın, aristokrasinin ya da birey olarak sanatçının kendisinin sanattaki üretim şekillerinin nasıl belirleyicisi olduklarını okumuşuzdur. Bahsettiğimiz süreçten günümüze, postmodern kavramının tartışllmaya başladığı 20. yüzyllın ortalarına kadar sanatın temel olarak iki gerçeklik kavraylşından bahsedilmektedir. Bunlardan ilki taklittir, yaşamı ne kadar iyi yansittı̆gldır. Çünkü algllar yoluyla elde edilen her bilginin kaynağı tanrıdır ve ona dayalı bir düzenin ürünüdürler. Gerçek olan oysa diğer şeyler onun taklididir. Ne kadar benzerse o denli iyidir. Zeuxis ve Parrhasius örneğini hatırlartz. İkincisi bireyin kendi gerçekliğinin yansitılmasıdır. Rönesans ile birlikte hümanizmin, rasyonalizmin ve sonrasında determinizmin bireyi, aklı ve bilimi, gerçeği kavramadaki ana yapılar haline getirmesi ile tanrının yerini insan/birey almış̧ır. Ortaya çıkan eserin içeriği de bu doğrultuda olmuştur.

Günümüzde ise bütün bunların dışında gerçeğin ne tanrının ne de bireyin merkeze alınmasıyla yapılamayacağı bir düşünce şekli olan postmodernist durum söz konusudur. Gerçeklik, eğer varsa kişiden kişiye, durumdan duruma ya da toplumdan topluma değişir. Dolaylsıyla gerçeklik de rölatiffgörece bir olgu durumundadır. Böylesi bir yapı zenginlik, karmaşa, kaos, simülasyon gibi kavramların beslediği; içi boş mu dolu mu muğlaklı̆̆ında devasa bir postmodern bulanıklğ̆ın ortaya çıkmasına sebep olmuştur. Sanat da bu süreçte her türlü araç gereç ve her türlü yaklaşımın bir arada bulunabildiği ve dahası herkes tarafindan yapılabilir bir yapıya dönüşmüştür. Bu alanda ortaya çılkan ürünlere kimse "bu sanat eseridir ya da değildir" diyememektedir. Çünkü rasyonalite ve determinizmin tanımlama ve tanımlayarak algılama şekli postmodernite tarafindan kullanılamaz. "Walter Benjamin, günümüzde sanat yapttlarında sinirsiz sayıda mekanik yeniden üretim (Reproduktion) yoluyla ortadan kalkmakta olan ve giderek kalkan şeyin ne olduğunu sorgulamıştır. Benjamin'e göre, ortadan kalkmakta olan şey, sözcüğ̈̈n en sağın anlamıyla "özgünlük'.' tür. Yeniden-yapım, sanat yapıtının özgünlüğ̈̈nü yapan ana öğeyi, "burada ve şimdi olma"yı ortadan kaldırmaktadır. Yani sanatın biricik ve zorunlu ölçütü olarak özgünlükten söz etmek artık olanaksızlaşmaktadır."(Frenzel, 1990, 78) Neyin gerçek olup olmadı̆̆ını, neyin sanat olup olmadığını tartışmıyorsak ve bu olguları günümüz içindeki yeri bağlamında tanımlamıyorsak bu durumda neden bahsedilebilir? Her şey gerçek ve hiçbir şey gerçek değil önermesinin paradoksu içerisinde bireyin duyduğu iç huzursuzluğu ne dindirebilir? İnsan içgüdüsel olarak alglladıklarını anlamlandirarak ve kendinde bir tanım oluşturarak bilinemezliğin huzursuzluğundan kurtulabilir. Nitekim genel olarak postmodernizm dediğimiz bu yapıyı da tanımlamaya açıklamaya çalı̧̧maktadır. Oysa ki postmodernizm tanımlamaların ya da büyük anlatıların dişında olduğunu söyleyerek, kendine bir tanımlamayla sınırlandırmakta sınır, sinırsızlıktır diyerek başka bir paradoksa sürüklemektedir.

Yaklaşı yetmiş yıldır üretilen eserlere baktı̆gımızda ne denli avangard olursa olsun artık klasikleşmiş ilk örneklerinin düşünce olarak yinelenmelerinden başka bir şey göremiyoruz. Bütün bunun sonucunda özne olarak insanin yaşamsal dengesini bulabilmesi gerekecektir. Adl 
her ne olursa olsun bireyin anlamlandırma içgüdüsü tüm karmaşık yapının mutlaka çözümlenmesi ve her ne kadar postmodernizm tanımlamalardan uzak da duruyor da görünse mutlak suretle yerini yeni bir yapıya bırakırken tanımlanmış ve belki de klasikleşmiş olacaktır.

Anahtar Kelimeler: Postmodernizm, anlamlandırma, huzursuzluk, modernizm.

\title{
Signification Of Postmodern Art And Individual's Internal Discomfort
}

\begin{abstract}
Art had taken on functions that show variability in different periods as a superstructure since the time period that had existed. We know art works that were created for several reasons such as to provide information, to testify, to manage perception, expression, and certification. We have read how the sorcerers in the cave periods, clerics in the Middle Ages, bourgeois class in the Renaissance, aristocracy or artist himself as an individual were determiners of the production types in art. From the above mentioned period until the mid-20th century when the concept of postmodern was first discussed, basically two perceptions of reality were mentioned. The first of these is imitation, how well it reflects the life. Because source of the any information that obtained through the senses is God and they are the product of a scheme based on that. If God is real other things are just the imitation of him. How much similar, that much good. We remember the Zeuxis and Parrhasius instance. The latter is the reflection of the individual's own reality. With Renaissance by humanism, rationalism and after determinism transforming wisdom and science as the main structures in appreciating reality, God was replaced with person/individual. Hence the content of resulting work was in this direction too.

Today the postmodernist situation is the case that neither God nor individual is centralized. Reality if exists, changes person to person, case to case or society to society. Thus reality is a case of relative phenomenon. A structure like this caused such a gigantic equivocal postmodern turbidity that was fed by concepts such as prosperity, perplexity, chaos, and simulation. In this process art was converted to a structure that all kinds of tools and materials and approaches could coexist and moreover could be performed by anyone. Nobody can say "this is art or not" to the products that revealed in this era, because definition and perception by definition methodology used by rationalism and determinism is not used by postmodernity. "Walter Benjamin has questioned what is being vanishing or has gradually vanished by unlimited mechanical reproduction. According to Benjamin that being vanished is exactly originality. Reproduction destroys "being here and now" which is actually the main component of art work's originality. So it impossible to talk about originality as the art's unique and compulsory criteria anymore" (Frenzel, 1990, 78). If we don't discuss what is real or unreal or what is art or what isn't, and if we don't describe these phenomenon in context of their place in today's life, then what can we talk about? What can stop the individual's internal discomfort in the paradox of everything is real and nothing is real statement. Man/Person can get rid of the discomfort of obscurity by instinctual signification of what they perceived and forming a selfdefinition. As a matter of fact tries to define and clarify the structure that we call postmodernism in general. However postmodernism makes a definition by saying that it was outside the definitions or the grand narratives. But it drugs us to another paradox by saying "defining the limit is unlimitedness".
\end{abstract}

When we look at the works of art produced in the past 70 years no matter how avant-garde they are, we cannot see anything else but the repetition of the first vintage examples. Consequently as a subject an individual is supposed to find his/her vital balance. Although postmodernism seems to stand away from identification, this confusing structure will be resolved, significated and maybe classical with resulting in the individual's instinctional signification, whatever it is named.

Keywords: Postmodernism, signification, discomfort, modernism.

Bu araștırmada elde edilen bulguların bir bölümü veya tamamı 12-14 Kasım 2015 tarihleri arasından düzenlenen "Felsefe, Eğitim ve Bilim Tarihi" adlı sempozyumda sözlü bildiri olarak sunulmustur. 


\section{Anlamlandırmanın Gerekliliği}

Her birey yaşamının devamlılığı açısından içgüdüsel olarak bazı davranışlar sergiler. Karnını doyurur, barınır, neslini devam ettirir, çevresini algılar ve anlamlandırarak onun kendisi için olumu ve olumsuz yanlarını belirler. Tüm bu edimleri sürecinde gerçekleşecek istenmeyen hareketlenmeler, değişiklikler, yaşamsal açıdan bireysel iç huzursuzluğa neden olmaktadır. Çevresinde oluşan değiş̧iklikler, düzen farklılaşmaları birey tarafından anlamlı hale geldiğinde duyulan iç huzursuzluk başka bir duyguya dönüşerek ortadan kalkar. Tüm bu değişiklikler anlamlandırma sonrasında birey için bir tehlike oluşturuyorsa, bu tehlikenin niteliğine göre kendini ayarlayan birey olumlu bir değişiklik karşısında da onu kabul edecek ve bundan haz duyabilecektir. Bu da bireyin yaşam kalitesinin artmasına neden olacaktır. Aslında bütün bu paragraf boyunca söylediklerimizin bizdeki karşılığı çoğunlukla milisaniyelere denk gelmektedir. Bütün bu akıl yürütme sonucunda birey kendisini ve çevresini doğru konumlandırabilmektedir.

Ancak bireylerin bu anlamlandırma sürecinde yaşantısı boyunca o güne kadar elde ettiği bilgi birikimlerinin önemli oluşu ve bu bilgilerin her bireyde farklı şekillerde kodlanması türdeş hatta aynı değişkenlerin her bireyde farklı tepkiler doğmasına neden olmaktadır. İşin bu kısmı bir yönüyle çeşitliliğin güzelliğini göz önüne sererken diğer taraftan sanat gibi öznelliği daha fazla olan alanların incelenmesi ve konumlandırılması durumlarında ciddi bir belirsizlik ortamı oluşturmaktadır.

Bir belirleme yapmak, nokta koymak ya da bir tanıma sokmak insan aklı için rahatlatıcı bir yoldur. Çalışma şekli gereği bunu tercih eder. Bu tanımlama, tanımlayarak açıklama edimi, günümüzde postmodern yapı tarafından eleştirilen determinist yaklaşımdır. Özellikle modernizmin temel dinamiklerini oluşturan sürekli yeninin aranması, bulunması çabasında bireyin pozitivist düşünce ve determinizmden yola çıktığını biliyoruz. Sonrasında modern düşüncenin yaşamı, bireyi ve insanlığı birleştirmek yerine tam tersine ayrıştırdığı, sınırlandırdığı, sınıflandırdığı gerekçesiyle eleştirildiğini görüyoruz. Elbette her sistem kusursuz değildir. Sistemlerin kusuru, sistemleri kullanarak çıkarlarını gözeten bireylerin her zaman bulunacak olmasıdır. Ancak her ne kadar günümüzün postmodern algısı tarafından modernite kısır, kuralcı, katı, hatta belirli sınıfların amaçlarına hizmet ettiği düşüncesiyle faşist olarak nitelendirilerek yerden yere vuruluyor olsa da olayları, şeyleri kavramamızda bize sunduğu yöntemler açısından bakıldığında önemlidir. Ve aslında her ne kadar eleştiriler onun bu yöntemlerine yapıllyor da olsa eleştirenlerin savunduğu zengin postmodern muammasını tanımlarken yine modernitenin yöntemlerini kullanıyor olmaları da ayrı bir muammayı ortaya koymaktadır.

Bireysel olarak çevremizi yaşamsal açıdan varlığımızı sürdürebilme içgüdüsü ile sürekli tarar ve anlamlandırırız. Bir bilim dalı olarak tüm insanlığa doğru bilgiyi arayan alanlar için ise bu neredeyse bir zorunluluktur. Bu zorunlulukla bugünden baktığımızda geçmişi anlamamızı, şimdiyi yorumlayabilmemizi ve gelecek için öngörülerde bulunabilmemizi sağlarız ki bu da huzursuzluğu ve belirsizliği en aza indirmek içindir.

\section{Postmodernitenin Belirsizliği}

Ortaya çıkışından bu yana yarım yüzyıla yakın zaman geçmiş de olsa postmodernizmin ne olduğu ile ilgili tartışmalar hala sürüp gitmektedir. Tanımı net olarak yapılamamaktadır. Postmodernizm içerisinde onu olumlayan veya eleştiren pek çok düşünür, eleştirmen, sosyolog ya da sanatçı durumu nitelemek için çok farklı tanımlar yapmışlardır ki bu tarafiyla bile bir belirsizliği vurgulamaktadır. Jameson durumu geç kapitalizm'in kültürel mantığıdır olarak tanımlarken, Foucault bilmeceli ve rahatsız eden bir dönem olarak nitelendirmektedir. Ya da Baudrillard'a göre,'taklitler, hipergerçeklik ve nihilizm dönemidir. Roland Barthes postmodernizm için "nazik bir mahşer anıdır" demiştir. Berman'a göre, katı olan her şeyin buharlaştı̆̆ı dönemdir. M. Sarup’a göre, muğlaklık 
dönemidir. Feyereband'a göre ne olsa gider denilen her şeyin egemen olduğu dönemdir. Gellner postmodernizmi aşırı göreliliğin ve öznelciliğin hakim olduğu bir yapı olarak tanımlamaktadır.

Bakıldığında tanımların büyük kısmında yapı olarak bir belirsizlik durumu görülebilir. "Her şey bir yana, açık olan şu ki postmodernist inancın 39 ilkesi ya da postmodernist manifesto diye bir şey yok ki, ona bakıp içerdiği tasarımları tam anlamıyla belirleyebildiğimizden emin olalım."(Gellner, 1992, 23)

Ancak daha önce de belirttiğimiz gibi yeni olan bir şey kendisini eski üzerinden var etmektedir. Dolayısıyla modernizmin temel özellikleri ve parametreleri üzerinden hareket ederek postmodern yapıyı algılayabilir ve belirsizliklerini, muğlaklığını kavrayabiliriz. Ayrıca postmodernizm kendini modernizmin hemen tüm yapılarına bir karşı duruş üzerinden tanımladığ 1 için modernizmin özelliklerinden hareket etmemiz bir zorunluluk olarak karşımıza çıkar. Pozitivizm, rasyonalite, determinizm, ulus-devlet anlayışı, endüstrileşme, kapitalizm postmodernizm tarafindan eleştirilen modernist yapılardan bazılarıdır. Buna karşılık, belirsizlik, çoklu gerçeklik anlayışı, farklılık, etnik olan, kültürel çoğulculuk, yerel bilgi, liberal ekonomi politikaları ön plana çıarılmaktadır.

Felsefe bazında postmodernizmde Nietzsche ve Heidegger'in etkisiyle şekillenen bir düşünce yapısıyla karşılaşırız. "Nietzsche'ye göre evrenin, bir tek değil sayısız anlamı vardır ve bu durumda bilginin tek bir gerçekliğin temsili olduğu tezi tutarsızdır. Yani Nietzsche'ye göre doğru bilgi görelidir, gerçeğin temsili diye bir şey olamaz, onun yerine yorumlar vardır."(Şaylan, 2009, 23) Ak1l yoluyla elde edilen bilginin tekilliği ve gerçekliği çoklu bir gerçekliğe ve dahası yorumların bilgi olarak kabulü algılamada daha kaotik bir yapıyı karşımıza çıkarmaktadır. İnsanoğlunun yoksulluğunu, acısını ya da bilgiye açıllğını gidereceği düşünülen modern bilim ve bilgi; tam tersine teknoloji güç, bir zümrenin diğer zümreleri bu gücü elinde tutma amaciyla kullanması nedeniyle insanlığa mutsuzluğu, savaşı yıkımı getirdiği düşüncesiyle eleştirilmiştir. Dolayısıyla postmodernistler için akıl bilginin kaynağı değildir. Ve bilginin doğruluğu tek ve genel geçer değildir. Bu durumda her bir farklı coğrafya, mekan ya da ortam dahilindeki her bir bireyin gerçeklik ve bilgi kabulü farklı olacak ve asıl karmaşaya neden olan tarafı, bunun diğerleri tarafından kabul edilip edilmemesinin önemli olmayacağıdır. Feyerabent'in postmodernizm için belirttiği 'ne olsa gider' düşüncesinin egemen olması da bunu ortaya koymaktadır. Bu duruma Şaylan "Toplumun kendini yeniden üretememe paradoksu" demektedir.(Şaylan, 2009, 35) Herkesin kendi gerçeklik algısı ve doğrusu farklı ise bu durumda toplumlar nasıl toplum olabilir? Toplum olma vasfinın ortadan kalması ve kendini üretememesi durumunda ise onlar için bir başka yapı tarafından üretilmiş yapıyı kabul ederler. Kanımca bu postmodernizmin gizliden gizliye bir kabullenme kültürü olduğunun da göstergesi durumundadır.

Çoklu gerçeklik algısını güçlendiren bir diğer etken de bilim ve bilimin evreni, gerçeği kavrayışındaki değişmelerdir. Galileo'nun cismin neden değil de nasıl yere düştüğü ile ilgilenmesi modern bilimin esasını teşkil etmektedir. Modern bilimde nedensellikten ziyade nasıllık önemlidir. Nasıllık doğrultusunda oluşan modern bilim, evrenin ve gerçeğin kavranışında her şey birbiriyle mantıksal bir ilişki içinde olduğunu, ilişkinin mükemmel bir şekilde işlediğini düşünmektedir. Einstein'in İzafiyet Teorisi ya da Bohr'un Qauntum fiziği ve Heisenberg'in Belirsizlik Kuramı ile bu anlayış sarsılmıştır. Quantum fiziğine göre maddenin en küçük birimi olan atom paçacıkları arasında nedensel değil, rastlantısal bir ilişki vardır. Bundan sonra suje-obje ayrımı yıkılmış ve rastlantısallık ilkesi kabul edilmiştir. Postmodernizmin en revaçta kavramlarından bazıları arasında rastlantı ve kaosu görebiliriz. Suje-obje ayrımının ortadan kalkması ile modern bilimin tarafsızlık ilkesi de yıkılmış olmaktadır. Çünkü Quantum kuramına göre bilgiyi üreten kişi ile bilgi arasında bir bağlantı söz konusudur. Bilgiyi üreten kişinin değer yargıları, kişiliği, dünya 
görüşü bilgiyi etkilemektedir. Dolayısıyla karşımıza yine çoklu bir gerçeklik algısı çıkmaktadır.

Toplum yapısının çoklu bir gerçeklik algısı içerisinde kendini üretememesi aslında toplumun belirlenememesi anlamına gelmektedir. Dolayısıyla toplumsal bir kuramdan söz etmek de olanaksızdır. Aslında bu durum tam olarak bir sosyolojinin ortadan kalkması durumu değildir. Sadece sosyolojik olarak kesin çıkarımlar yapmanın mümkün olamayacağı, sadece verilerin yorumlanabileceği düşünülür $\mathrm{ki}$, sosyolojik açıdan çoğulculuğu vurgulayan postmodernizm hermeneutic'i kullanarak bunu uygular. Özellikle Gadamer tarafindan ele alınan hermeneutic 1950'lerde Iser ve Jauss tarafindan edebi metinlerde kullanılmış ve alımlama estetiği olarak postmodernitenin önemli yöntemlerinden biri olmuştur.

Postmodern toplum yapısıyla ilgili ilk görüşleri ortaya atan kişiler Baudrillard, Lyotard ve Jameson olmuştur. Lyotard modernizme ait olan büyük anlatıların sanayi toplumuna dair bir epistemolojinin ürünü olduğunu ve değişen sanayi toplumuna/sanayi sonrası topluma hizmet eden yeni bir epistemolojinin oluştuğunu ile sürerek bu anlatıların geçersizliğini savunur. Lyotard'a göre, postmodern meta anlatılar karşısında kuşkuculuk ve metafizik felsefenin, tarih felsefelerinin ve herhangi bir totalleştirici düşünce biçiminin (Hegelcilik, Liberalizm, Marksizm ya da buna benzer) reddi olarak tanımlanır. Dolayısıyla postmodern bilgi farklılıklara duyarlı olma özelliğimizi geliştirir ve başka bir şeyle kıyaslanamaz olanı hoşgörme yetimizi pekiştirmektedir (Kellner, 1993, 237). Burada da farklılıkları hoşgörme yetimizden bahsederek, postmodernizmin kabullenme kültürüne yönelik tarafi vurgulanmaktadır. Kellner, Lyotard'ın büyük anlatılardan kurtulan bireyin özgürleşeceği ile ilgili söylemini şöyle eleştirir:

"Bence bu durumda bir kaos ortaya çıkmaktadır. Her türlü doğrunun yan yana olacağl ve kesin bir doğrunun olmayacă̆ bir toplum özgürleşmekten ziyade adaletin sağlanamayacă̆ kaos ortamina dönecektir.

Lyotard da aslında bu durumun farkında olmalı ki 'Çoğulcu adalet' kavramını ortaya atar. Fakat bu durumda da çok saylda adalet görüşünün olduğu bir toplum tam bir kaos ortamı ve anarşiye dönüşecektir. 'Adil olan nedir?' sorusuna verilen çok sayıda farkl cevabın yan yana oluşu toplumun kendini üretememesine sebep olacaktır."(Kellner, 1993, 234)

Görüldüğü üzere yine bir belirsizlikle karşı karşıya kalmaktayız. Bu vurguyu Baudrillard'da da görmek mümkündür. Baudrillard postmodern toplum yapısının oluşumunda yukarıda bahsettiğimiz çoklu gerçek algısında da etkisi olan hiperrealite, simülasyon ve implosion(içe patlama) kavramlarının etkili olduğunu öne sürer. Baudrillard'a göre, modern endüstri toplumunun anahtarı üretimken, postmodern toplumda "gerçek" i önceleyen modeller olarak "taklitler" toplumsal düzene egemen olmaya toplumu "hipergerçeklik" olarak oluşturmaya başlar. "Sanayi ötesi toplumda Baudrillard'a göre artık insanlar gerçeğe bakarak modeli değil, kendilerine sunulan modele bakarak kurgusal gerçeği belirlemektedirler. Mesela, insanlar arzuladığ l, oturmak istediği evi dergiler, reklamlar, Tv belirlemekte, bunlar insanlara modeller sunmaktadır. Böylece insanlart işaretler ağl etkilemektedir."(Şaylan, 2009, 203) Bu yüzden sanayi ötesi toplumda 'hiperrealite' hakimdir. Postmodern çağda toplumlar gerçekle değil, gösteri ile ilgilenmektedir. Bu gösterinin merkezinde de 'simulakr'lar bulunmaktadır. Yani yaşamdaki varlıkların taklitleridir. Bunlar insan ve toplum yaşamı ile ilgili taklitlerdir. Fakat bu taklitler gerçeği yansıtmamaktadır $\mathrm{Bu}$ yüzden bir 'hiperrealite'den bahsedilmektedir. Böyle taklitlerden ve kurgudan örülü bir toplumda doğru ve yanlışın ne olduğuna karar vermek olanaksızdır. Çünkü gerçeğin ne olduğu konusunda belirsizlik ve önemsizlik vardır.

Postmodernizmin belirsizlik yaratan diğer bir ana damarı da dil olgusudur. Dil, modernist anlayış içerisinde nesnel gerçekliği ifade etmektedir. Fakat gerçekte dilin paradoksal ve 
metoforlara dayalı bir yapısı vardır. Postmodernistler, herkesçe bilinen Giritli Epimenides'in paradoksundan yola çıkarak her durumda dilin nesnel gerçekliği temsil edemeyeceğini savunurlar. Epimenides önermesinde 'Bir Giritli olan Epimenides bütün Giritliler yalancıdır diyor' der. Bu bir dil paradoksudur. Çünkü Tüm Giritliler yalancı ise Epimenides de yalanc1 olur ve o zaman Giritliler nasıl yalanc1 olacaktır. Bu dilin özelliğinden kaynaklanan bir açıktır. Bu bilgi test edilemez. Yani dilin bu özelliği de göze alınarak tek değerli mantık ya da doğruluk yerine çok değerli mantık kabul edilmiştir. Postmmodernizmin bu savı Derrida'nın görüşlerinde karşılık bulmaktadır. Derrida'ya göre dilin bu özellikleri nedeniyle dış dünya ancak göreli olarak ifade edilebilir ve anlam okuyucudan okuyucuya değişebilir. "'Derrida'ya göre herhangi bir metni okuyan ya da mesaj alan birey, sembollerin kodunu çözüp metni anlamlandıracak ya da bir başka deyişle semantik yüklemesi yapacaktır. Ancak bir metni okuyan bireyin semantik yüklemesi ile metni kaleme alan bireyin yaptı̆̆ semantik yükleme arasında daima şu ya da bu ölçüde bir fark bulunacaktır-anlam-landırma farkl. "(SSaylan, 2009,173)

Anlamlandırmanın bireylere göre farklı oluşu ve anlamın çok katmanlılı̆̆ı ile ilgili belirlemelerin arkasında, 1960'larda Konstanz Üniversitesi'nde edebiyat alanında araştırmalar yapan ve bu araştırmalar sonucunda alılmama estetiği düşüncesini ortaya atan Jauss ve Iser'i görebiliriz. Özellikle Jauss edebiyatta eser ile izleyicinin arasındaki anlamlandırma sürecini inceler. Alımlayıcı burada asıl belirleyicidir ve anlam her bireyde farklı şekillerde somutlaşacağ gibi aynı bireyde farklı zamanlarda da farklı olarak somutlaşabilir.(Özal, 2015, 465) Aslında gerek Iser'in gerek Jauß'un üzerinde durdukları yapı edebiyat alanında olsa bile tüm sanat alanları için uyarlanabilir. Herhangi bir sanat eseriyle karşılaşan bireyin/alımlayıcının bu yapıtın içerisindeki göstergelerden elde ettiği ampirik bilgiyi kendi donanımıyla birleştirerek sürekli farklı okumalar yapmasını sağlayan anlamlandırma sürecinin ortaya konmasıdır. Bu durum aslında günümüz yaşantısının hemen her alanında karşımıza çıkar ki Nietzcshe'nin evrenin, bir tek değil sayısı anlamı vardır ve bu durumda bilginin tek bir gerçekliğin temsili olduğu tezi tutarsizdır.(Özal, 2015, 466) Jauss ve Iser'ın alımlayıcıyı ve alımlayıcıda oluşan çoklu anlam katmanlarını merkeze alan görüşleri postmodernizmin tüm yukarıda da bahsettiğimiz belirsizliğini destekler niteliktedir.

\section{Sonuç}

Postmodernizmin konuşulmaya başlandığ 120 . Yüzyılın ikinci çeyreğinden bu yana yukarıda bahsettiğimiz tüm gelişmeler birbirini destekleyerek ve güçlendirerek günümüzün çoğul ancak belirsiz gerçeklik algısını oluşturmaktadır. Bilim, siyaset, felsefe ve bunlarla bağlantılı olarak kültür ortamında algının çok anlamlılık üzerine kurgulanması ile gerçekleştirilen belirsiz, muğlak yapı sanat alanını da kuşatmış görünmektedir. Her bireyin doğru ve yanlışlarının farklı olmasının ötesinde doğru veya yanlış gibi tanımlamaların önemsiz oluşu, büyük anlatıların yerini yerel ve hatta bireysel hikayelerin alması, alımlama estetiği ile izleyicinin neredeyse sanatçının yerini alması; aynı zamanda bütün bahsi geçen yapıların günümüz ekonomisi için birer yeni pazar oluşturması kafa karışıklığını destekleyen ve buradan beslenen neo liberal sistemlerin, Adorno'nun tabiriyle bir 'kültür endüstrisi'nin oluşmasına neden olmuştur. Bir endüstriden bahsediyorsak eğer üretim-tüketim ve kârdan bahsediyoruzdur. "Kapitalizmde bütün üretim piyasa içindir; mallar insan ihtiyaçlarını ve arzularını karşılamak için değil, kar elde etmek için, daha fazla semaye edinmek için üretilir".'(Adorno, 2014, 14) Kapitalizm bu acımasız amaca ulaşmak ve sürekli canlı tutmak için her türden gelişmeyi izler, inceler, onda kendi amacına hizmet edebilecek, kullanabileceği kısımları alır ya da kendine zarar verebilecek tüm oluşumları, güçlerini kullanarak ortadan kaldırmaya, hafızadan silmeye çalışır.

Modernizmin elitist tavrına karşılık eklektik bir tavır barındıran ve eskinin yeniyle, gelenekselin modernle, eşzamanlılık içerisinde bir arada durabilmelerini ve 
yadırganmamalarını sağlayan postmodernizm kapitalist algının en önemli oyun alanlarından birisi olmuştur. Hatta sanat alanında postmodernizmi Steyerl şu şekilde tanımlamaktadır, "Kapitalizm nasıl daha güzel gösterilebilir?" sorusunun yanitıdır."(Steyerl,2013: 1) Postmodernizmin bu eklektik yapıs1 içerisinde hemen her şeyin sanat eseri ve herkesin sanatçı olarak kabulü, Duchamp'ın hazır nesneleriyle başlayan sanatın kavramsallaşma süreciyle birlikte, sanat eserinde biçimin, sadece esas olan fikri, anlamı taşıyıcı bir yapıya dönüşmesini sağlamış; biçimin, formun anlamını yitirmesiyle birlikte doğrudan anlamla karşı karşıya kalan izleyicinin neyin sanat eseri olduğu ya da kimin sanatçı olduğu ile ilgili akıl karmaşasına düşmesine neden olmuştur. Baudrillard'ın toplumun sonunun geldiğini söylediği 'Game With Vestiges' adlı makalesinde postmodernizmin, modernliğin yıkıntılarından arta kalanlarla oynanan bir oyun olduğunu söyler. Ancak bu oyun salt çocuksu bir merak ya da varolduğu evreni kavramaya ve kendisini var etmeye yönelik bir oyun değildir. Durumun kendisi de bir simülasyon olarak kendisini üretemeyen/var edemeyen toplumlara nasıl yaşayacaklarına, nasıl algılayacaklarına, evlerini nasıl şekillendireceklerine ve hatta nasıl öleceklerine dair simülasyonlar üreten zümrelerin kontrol mekanizmalarıdır. Mekanizmalar ise medya, teknoloji, kültür ve sanat aracılığıyla toplum algısını belirsizleştirme yönünde domine eden çarklardan oluşmaktadır.

Sonuç olarak böylesi bir karmaşa içerisinde bireyin düştüğü iç huzursuzluğu, onu, kendi içerisine dönmesine ve kendi deneyimleri, bilgi birikimi ve dünya görüşü çerçevesinde durumu anlamlandırmaya itmektedir. $\mathrm{Bu}$ durumda ise bireyin önünde iki yol görünmektedir. Matrix filmindeki başkarakter Neo gibi uyanarak Platonun mağara metaforunun, Baudrillard'ın göstergeler imparatorluğunun farkına varacak ve 1988 yılı yapımı olan "They Live" filmindeki başkarakter John Nada gibi acı çekecek ve çevresine bunu anlatmaya çalışacaktır. İkinci yol ise gördüğü her şeyi kendince yorumlayarak hayatını şekillendirdiği yanılsaması içerisinde "her şey olabilir" düsturunu benimseyip ekonomi politikalarının oluşturduğu kültür endüstrisinin küçük dişlilerinden birisi olarak hayatını sürdürebilir. Dahası günümüz sanat ortamında sergilenen görüntüler karşısında bunun bir sanat eseri olup olamayacağı; bir bienal dahilinde gördüyse herhalde bir sanat eseri olacağı kanısına vardığı sırada ona çok benzer bir görüntüyü sokakta gördüğünde ise bunun da bir sanat eseri olabileceği; hatta bunu kendisi fark ettiği için kendisinin de sanatçı olduğuna hükmedebilecek bir bireysel alg1 sahibi olabilir. Ya da bunun tam tersi olarak sokaktakinden sonra sergilenen şeyin bir anlamı olmadığını da düşünebilir. İşin en karmaşa yaratan tarafi ise her iki durumun çok da önemli olmadığı düşüncesinin postmodernizmin düsturu olmasıdır.

\section{Kaynakça}

Adorno, T.W., (2014), Kültür Endüstrisi Kültür Yönetimi, (N. Ülner, M. Tüzel, E. Gen, Çev.), İstanbul: İletişim

Baudrıllard, J., (1991), Sessiz Yığınların Gölgesinde Ya da Toplumsalın Sonu, (ADANIR, O., Çev.), İstanbul: Ayrıntı.

Baudrillard, J.(2014), Sanat Komplosu, Yeni Sanat Düzeni ve Çağdaş Estetik 1,(E. Gen, I. Ergüden, Çev.), İstanbul: İletişim

Bernman, M., (1994), Katı Olan Her Şey Buharlaşıyor, (Altuğ, Ü., Peker, B. Çev.), İstanbul, İletişim.

Doltaş, D., (2003), Postmodernizm ve Eleştirisi, Tartışmalar/Uygulamalar, İstanbul: İnk1lap

Frenzel, I., (1990), Günümüzde Felsefe Disiplinleri- Estetik, (Özlem, D. Çev.), İstanbul, Ara.

Gellner, E., (1992), Postmodernism, Reason and Religion, Londra: Routledge

Gıddens, A., (1998), Modernliğin Sonuçları, (E. Kuşdil, Çev.), İstanbul: Ayrıntı. 
Jameson, F.(1994), Postmodernizm ya da Geç Kapitalizmin Mantı̆̆ı, (N. Plümer, Çev.), İstanbul: YKY

Kellner, D., (1993) Toplumsal Teori olarak Postmodernizm: Bazı Meydan Okumalar ve Sorunlar, (KÜÇÜK, M., Çev.), Modernite Versus Postmodernite, Ankara: Vadi

Küçük, M., (2011), Modernite Versus Postmodernite , Ankara: Vadi

Özal, A.C., (2015), Günümüz Sanatına Şekil Veren Yapılar ve Sanatta Yeni Bir Yol Yanılsaması Olarak Alımlama Estetiği, "Sanat, Gerçeklik ve Paradoks Uluslararası Sanat Sempozyumu" Bildiri Kitabı, Muğla Sitkı Koçman Üniversitesi

Steyerl, H., (2013), Sanatın Politikası: Çağdaş Sanat ve Post-Demokrasiye Geçiş, (Z. Baransel, Çev.), Erişim tarihi: 03.04.2015, http://www.eskop.com/skopbulten/sanatin-politikasi-cagdas-sanat-ve-post-demokrasiyegecis/1433

Şaylan, G., (2009), Postmodernizm, Ankara: İmge 